\title{
The importance of progesterone in the maintenance of
}

\author{
pregnancy in the sheep
}

\author{
BRENDA M. SCHOFIELD \\ Ph.D., D.Sc. \\ Department of Physiology, Royal Veterinary College, London, N.W.1
}

\begin{abstract}
ALL MY investigations into the hormonal control of myometrial function have been carried out on lower animals. My first excursions into the ovine field were made, appropriately enough, with an obstetrician, Dr Bengtsson. We felt that someone should take up the challenge for the sheep, for Short \& Moore (1959) had reported that they could find no change in the level of blood progesterone at the end of pregnancy in ewes until after the delivery of the placenta. The implication was that in the sheep, a decline in the influence of progesterone is not a necessary prelude to parturition. We were unwilling to accept this and our first series of experiments (Bengtsson \& Schofield, 1960) involved recording the staircase effect shown by the myometrium, both in vivo and in vitro, the staircase effect being a functional test for progesterone dominance.
\end{abstract}

We were able to demonstrate a change from a negative to a positive staircase effect before parturition, a change which indicated that the myometrium becomes oestrogen-dominated before the onset of parturition, apparently regardless of systemic blood levels of progesterone. Our next experiments were designed to discover whether normal parturition could be delayed by the daily administration of progesterone to ewes from 1 week before term. The results constituted a negative answer to this question, for parturition either occurred at the normal time or, with large doses, was delayed indefinitely and the progesterone killed the foetuses (Bengtsson \& Schofield, 1963). This appeared to be evidence against the importance of a decline of progesterone influence prior to parturition.

For the last 4 years I have been working on ewes during the lambing season in Devon. In the 1st year we carried out a control series of experiments and recorded the events associated with normal parturition (Hindson et al., 1965). This was done with the aid of pressure-sensitive radiosondes implanted in the uterus 2 or 3 weeks before term so that intrauterine pressure changes could be recorded thereafter in the conscious ewe. The results showed that there are almost no pressure changes which can be ascribed to myometrial activity until the onset of parturition approximately $12 \mathrm{hr}$ before delivery of the lambs. Subsequently we repeated some of the experiments which Bengtsson and I had done, with a view to producing abnormal changes in the cervix, and we injected $80 \mathrm{mg}$ progesterone daily for a week before term (Hindson, Schofield \& Turner, 1968a). Although all the ewes delivered their lambs spontaneously at term, the amplitude of the pressure waves developed during parturition was less than that in control ewes and in half of the ewes labour was protracted. So it appeared that the progesterone was, indeed, having a depressant effect on myometriad function even though this could not be detected without careful recording of the intra-uterine pressure changes associated with parturition.

Recently, we have carried out experiments (Hindson, Schofield \& Ward, 1969) in which we injected a single dose of $80 \mathrm{mg}$ progesterone once the early stages of parturition were established. This injection was given only when: (a) pressure waves of greater amplitude than those due to body movements were recorded at least twice in $10 \mathrm{~min}$, (b) the cervical canal had begun to open, and (c) a response of increased intra-uterine pressure waves followed digital examination of the cervix. The progesterone was injected at this stage in six ewes and slightly later during parturition (as evidenced by the greater amplitude and frequency of the recorded waves) in two ewes. In the six ewes parturition was suppressed and the pressure waves were abolished or diminished for up to $118 \mathrm{hr}$. The response to digital examination was also abolished. The lambs were finally delivered from 53 to $172 \mathrm{hr}$ after the injection. In the remaining two ewes which were injected slightly later, the effect on parturition was much less and there was no diminution in the amplitude of the waves recorded. In one, labour was prolonged to more than twice the control length, but in the other ewe, labour was only slightly prolonged. The eight ewes delivered thirteen viable lambs and one dead lamb.

The importance of these experiments appears to lie in the demonstration that continued daily 
administration of progesterone from a week before term has a much less depressant effect on the performance of the myometrium at parturition than one single dose given in the early stages of parturition. This suggests that the regulatory mechanisms of the uterus are able to adapt to continuous high blood levels of progesterone and can successfully terminate pregnancy in spite of them. Thus the myometrium develops a kind of resistance to progesterone. Perhaps this is the normal mechanism whereby the myometrium of the sheep escapes from the progesterone block. If this be so, then it follows that a single injection of progesterone, given during the early stages in the development of this resistance, would have a significant effect in inhibiting it. The period of vulnerability is clearly limited, however, since in the two ewes injected somewhat later, the depressant effect of the progesterone was considerably reduced-as one might expect in the development of resistance.

In species where the main source of progesterone is the placenta, there appears to be an intimate hormonal relationship between the placenta and the myometrium with which it is difficult to interfere. For this reason there is little direct evidence in such species that progesterone has a depressant effect on the myometrium and it is interesting that, in the sheep at least, this is best done by careful timing of a single injection of progesterone. In several species there is good evidence that placental progesterone has a 'local' effect on the myometrium and that placental control is exercised locally, in contrast to the systemic control exercised by the ovaries. It is now 12 years since Csapo (1956) first enunciated the concept of local control by the placenta.

The sheep's uterus has two horns (one body and one cervix) and for the efficient delivery of twin lambs these should be presented singly at the cervix. To investigate the mechanism whereby this is achieved, radiosondes were implanted in both horns of the uterus (Hindson, Schofield \& Turner, 1968b) so that intra-uterine pressure waves could be recorded in the two horns simultaneously. It was found that the two horns were in hydrostatic isolation and that the horn carrying the presenting lamb developed pressure waves which were about double the amplitude of those in the other horn. In this way only one lamb at a time was presented at the cervix. It is interesting to speculate how this difference between the two horns was brought about. In the sheep, the placenta takes the form of numerous cotyledons applied all over the interior of the uterus and, in twin pregnancies, there is almost no overlap in the placentation of the two lambs (Hindson, personal communication; Steven, 1968). Thus, one is tempted to suggest that this is yet another example of local control by the placenta and that, in some way, the progesterone block exercised by the cotyledons of the presenting lamb declines somewhat more rapidly than that in the other horn so that a clear differential is achieved in the pressure waves developed by the two horns. If this be so, then the ewe is clearly a valuable experimental animal for the further investigation of this rather important parameter-the local controlling influence of the placenta.

\section{References}

Bengtsson, L.Ph. \& Schofield, B.M. (1960) Hormonal control of myometrial function during pregnancy in the sheep. J. Reprod. Fert. 1, 402.

Bengtsson, L.Ph. \& Schofield, B.M. (1963) Progesterone and the accomplishment of parturition in the sheep. J. Reprod. Fert. 5, 423.

Csapo, A. (1956) The mechanism of effect of the ovar an steroids. Recent Prog. Hormone Res. 12, 405.

Hindson, J.C., Schofield, B.M., Turner, C.B. \& Wolff, H.S. (1965) Parturition in the sheep. J. Physiol. (Lond.), $181,560$.

Hindson, J.C., Schofield, B.M. \& Turner, C.B. (1968a) Some factors affecting dilatation of the ovine cervix. Res. vet. Sci. 9, 474.

Hindson, J.C., Schofield, B.M. \& Turner, C.B. (1968b) Parturient pressures in the ovine uterus. J. Physiol. (Lond.), 195, 19.

Hindson, J.C., Schofield, B.M. \& WARD, W.R. (1969) The effect of progesterone on recorded parturition and on oxytocin sensitivity in the sheep. J. Endocr. (In press).

Short, R.V. \& Moore, N.W. (1959) Progesterone in blood v. progesterone and $20 \alpha$-hydroxypregn-4-en-3-one in the placenta and blood of ewes. J. Endocr. 19, 288.

StEven, D.H. (1968) Placental vessels in the foetal lamb. J. Anat. 103, 539. 